\title{
Progressive polyradiculoneuropathy in diabetes: correlation of variables and clinical outcome after immunotherapy
}

\author{
Safwan S Jaradeh, Thomas E Prieto, Lorri J Lobeck
}

\begin{abstract}
Objective-To quantify the progression of diabetic polyradiculoneuropathy-a condition in which immune factors have been implicated-after immunotherapy.

Methods-The study evaluated 15 consecutive patients with this condition. All patients were older than 40 . Four had type I diabetes and six were women. The duration of pre-existing diabetes varied from 2 to 20 years. The clinical presentation was dominated by painful progressive motor weakness, with or without exacerbation of sensory symptoms. The weakness involved all limbs, but was often asymmetric.

Results-Electrophysiological testing showed a predominantly axonal polyneuropathy, with more recent denervating polyradiculopathy. Analysis of CSF showed increased protein in 14 and oligoclonal bands in five. Quantitative autonomic tests showed abnormalities in all patients. Sural nerve biopsy was performed in 14 patients; all showed fibre loss and segmental demyelination, four had occasional onion bulbs, and 10 showed various inflammatory infiltrates. After immunomodulating therapy, there was no further deterioration and clinical improvement occurred in all patients. Sweat responses, cardiovascular reflexes, and sural nerve fibre density correlated best with functional outcome. There was no significant difference between plasmapheresis and intravenous gammaglobulin.

Conclusion-Immunotherapy may improve this condition, but only certain variables correlate with rapid therapeutic response.
\end{abstract}

(F Neurol Neurosurg Psychiatry 1999;67:607-612)

Department of Neurology, Medical College of Wisconsin, Milwaukee, WI, USA S S Jaradeh

T E Prieto

L J Lobeck

Correspondence to: Dr Safwan S Jaradeh, Department of Neurology, Medical College of Wisconsin, 9200 West Wisconsin Avenue,

Milwaukee, WI 53226, USA Telephone 001414454 5200; fax 0014142590469. Received 12 October 1998 and in revised form 26 April 1999 Accepted 6 May 1999 ing the past 3 or 4 years, we evaluated 15 diabetic patients with rapidly progressive polyradiculoneuropathy. We treated all patients with immunomodulating therapy and followed them up for at least 1 year. We review their clinical, electrophysiological, and pathological data.

\section{Methods}

The patients' case reports and laboratory data are summarised in tables $1-3$.

\section{PATIENT SELECTION}

We studied 15 diabetic patients referred to our neuromuscular centre for progressive weakness between 1992 and 1995. The diagnosis of rapidly progressive polyradiculoneuropathy was made clinically and established electrophysiologically. All patients presented with proximal and distal weakness of their lower limbs, and distal weakness of their upper limbs. Proximal upper limb weakness was present in eight patients, and equalled proximal lower limb weakness in six patients. Two had facial weakness and two required respiratory assistance. The weakness progressed over 2 months or more in all patients by history. Electrophysiologically, the diagnosis was made when sensory nerve responses were abnormal, and needle EMG showed neurogenic changes in proximal muscles of one upper and one lower limb and their corresponding paraspinal muscles. All patients with pain also had spinal CT or MRI studies to rule out other structural radicular lesions superimposed on a diabetic polyneuropathy. Other causes of neuropathy (hereditary, nutritional, metabolic, toxic, and paraneoplastic) were excluded clinically and by appropriate laboratory tests. All subjects had detailed standard neurological and ophthalmological examinations.

Asymmetry of weakness was defined as a difference greater than one MRC grade between one or more homologous muscle groups. The neuropathy disability score (NDS) was determined according to published references. ${ }^{78}$ It is composed of three subsets: weakness (NDSW), sensory (NDSS), and reflex (NDSR). The NDSW summates motor weakness as 1 (25\% deficit), 2 ( $50 \%$ deficit), 3 ( $75 \%$ deficit), or 4 (100\% deficit) for each of 21 muscle groups in the head, neck, and limbs. The NDSR grades each of the major five tendon reflexes as 0 (normal), 1 (reduced), or 2 (absent). The NDSS grades the sensation over the fingers and toes as 0 (normal), 1 (reduced), or 2 (absent) for each of the four primary sen- 
sory modalities. This is a standardised method with established validity in diabetic and inflammatory neuropathy. ${ }^{8}$ The values were measured at baseline and then at 6, 12, 24, and 52 weeks ( \pm 1 week). Given the impact of weakness on all patients, the severity of the neuropathy was rated primarily based on the weakness subset of the NDS.

\section{LABORATORY STUDIES}

These included screening studies for other causes of neuropathy including serum immunoelectrophoresis. All subjects had determinations of their haemoglobin A1C (8.40 (SD 1.15)). Renal function (blood urea nitrogen, creatinine, and 24-hour proteinuria) was also determined. All patients had creatinine values under $2.5 \mathrm{mg} / \mathrm{dl}$ and all maintained a stable renal function during the study period. All patients had CSF examination.

\section{ELECTROPHYSIOLOGICAL STUDIES}

We performed standard nerve conduction studies and EMG in all patients. All motor nerves were stimulated distally and proximally. Electrophysiological demyelination and partial motor conduction block were diagnosed based on criteria previously published. ${ }^{9}{ }^{10}$ Needle EMG evaluated distal and proximal muscles at the discretion of the electromyographer.

We also measured autonomic function in all patients. These tests included quantitative sudomotor axon responses (Q-SART), blood pressure and heart rate variation to Valsalva, deep breathing, and tilt manoeuvres. ${ }^{11}$

NERVE BIOPSIES

Fourteen patients had sural nerve biopsy. All nerve specimens were divided into three parts. One part was frozen in cooled isopentane in liquid nitrogen, and $8 \mu \mathrm{m}$ thick sections stained for routine light microscopy. We stained the samples with monoclonal antibodies directed toward various inflammatory cells: CD68 recognises macrophages, CD4 and CD8 recognise their respective $\mathrm{T}$ lymphocytes, and CD22 recognises B cells (Dako Corporation, Carpinteria, CA, USA). The second part was embedded in plastic for semithin sections. The third portion was used for teased fibre analysis. The density of myelinated fibres was determined from $1 \mu \mathrm{m}$ thin sections according to methods previously described. ${ }^{12}$ Given the significant fascicular variability, the final density was that averaged from four fascicles. For teased fibre analysis, we evaluated more than 50 fibres per specimen, each containing at least four internodes, and graded their abnormalities as follows: A (normal); B (myelin wrinkling); C (segmental demyelination alone); D (segmental demyelination/ remyelination); F (segmental remyelination alone); and $\mathrm{E}$ (wallerian degeneration). ${ }^{8}$

\section{TREATMENT PROTOCOL}

Given the clinical similarity between diabetic rapidly progressive polyradiculoneuropathy and chronic inflammatory polyradiculoneuropathy, we applied similar treatment protocols. Although these treatments have not been fully evaluated in diabetic rapidly progressive polyradiculoneuropathy, we chose them based on accepted guidelines to treat chronic inflammatory polyradiculoneuropathy. All patients received immunomodulating therapy for the first 6-8 weeks. Patients 1 to 9 received three sessions of plasmapheresis weekly for one week, followed by two sessions weekly for 2 weeks and then one session weekly for 2 weeks. The total volume of exchanged plasma was 400

Table 1 Clinical features of patients

\begin{tabular}{|c|c|c|c|c|c|c|c|c|c|c|c|}
\hline No & Sex & $\begin{array}{l}\text { Age } \\
(y)\end{array}$ & $\begin{array}{l}\text { DM typel } \\
\text { duration }(y) / \\
\text { HbA1C (\%) }\end{array}$ & Pain & $\begin{array}{l}\text { Sensory } S x / \\
\text { duration } \\
\text { (months) }\end{array}$ & $\begin{array}{l}\text { Motor } S x / \\
\text { duration } \\
\text { (months) }\end{array}$ & $\begin{array}{l}\text { Trunk/vertex } \\
\text { sensory loss }\end{array}$ & Autonomic $S x$ & $\begin{array}{l}\text { Hypertension/ } \\
\text { kidney/retina }\end{array}$ & $\begin{array}{l}\text { Weight } \\
\text { loss (kg) }\end{array}$ & $\begin{array}{l}\text { CSF Protein } \\
\text { (mg/dl) }\end{array}$ \\
\hline 1 & $\mathrm{~F}$ & 42 & $\mathrm{I} / 20 / 8.5$ & No & $\mathrm{LE} / 24$ & $\begin{array}{l}\mathrm{LE}>\mathrm{UE} / 12 \\
\text { asymmetric }\end{array}$ & $\mathrm{No} / \mathrm{No}$ & CV, GI, P & Yes/Yes/Yes & 5 & 84 \\
\hline 2 & M & 52 & $\mathrm{II} / 14 / 8.7$ & No & $\mathrm{LE}>\mathrm{UE} / 6$ & $\begin{array}{l}\mathrm{LE}>\mathrm{UE} / 3 \\
\text { asymmteric }\end{array}$ & Yes/No & & $\mathrm{No} / \mathrm{No} / \mathrm{Yes}$ & 10 & 170 \\
\hline 3 & M & 53 & $\mathrm{I} / 16 / 7.3$ & LB & $\mathrm{UE}>\mathrm{LE} / 24$ & $\begin{array}{l}\mathrm{LE}>\mathrm{UE} / 4 \\
\text { asymmetric }\end{array}$ & Yes/Yes & CV, GI, P, S & Yes /Yes/Yes & 14 & 76 \\
\hline 4 & M & 59 & II $/ 10 / 8.7$ & No & $\mathrm{LE}+\mathrm{UE} / 12$ & $\begin{array}{l}\mathrm{LE}+\mathrm{UE}+\mathrm{R} / 2 \\
\text { symmetric }\end{array}$ & Yes/Yes & CV, GI, P, S & Yes/Yes/No & 10 & 42 \\
\hline 5 & $\mathrm{~F}$ & 60 & $\mathrm{I} / 5 / 7.5$ & LB & $\mathrm{UE}>\mathrm{LE} / 6$ & $\begin{array}{l}\mathrm{LE}>\mathrm{UE} / 3 \\
\text { asymmetric }\end{array}$ & $\mathrm{No} / \mathrm{No}$ & $\mathrm{CV}$ & Yes/Yes/Yes & 9 & 56 \\
\hline 6 & M & 60 & II $/ 10 / 8.3$ & LB & $\mathrm{LE} / 4$ & $\begin{array}{l}\mathrm{LE}>\mathrm{UE} / 6 \\
\text { symmetric }\end{array}$ & No/No & GI & $\mathrm{No} / \mathrm{No} / \mathrm{No}$ & 10 & 135 \\
\hline 7 & $\mathrm{~F}$ & 66 & $\mathrm{II} / 2 / 8.9$ & LE & $\mathrm{LE} / 5$ & $\begin{array}{l}\mathrm{LE} / 4 \\
\text { asymmetric }\end{array}$ & $\mathrm{No} / \mathrm{No}$ & $\mathrm{CV}, \mathrm{P}$ & $\mathrm{No} / \mathrm{No} / \mathrm{No}$ & 25 & 71 \\
\hline 8 & $\mathrm{~F}$ & 71 & II $/ 18 / 9.8$ & LB, LE & $\mathrm{LE} / 12$ & $\begin{array}{l}\mathrm{LE}>\mathrm{UE} / 2 \\
\text { symmetric }\end{array}$ & Yes/Yes & & $\mathrm{No} / \mathrm{No} / \mathrm{No}$ & 5 & 90 \\
\hline 9 & $M$ & 71 & $\mathrm{II} / 10 / 7.9$ & LE & $\mathrm{LE} / 12$ & $\begin{array}{l}\mathrm{LE}+\mathrm{UE}+\mathrm{R} / 5 \\
\text { asymmetric }\end{array}$ & Yes/No & $\mathrm{CV}, \mathrm{S}$ & Yes/No/No & 14 & 125 \\
\hline 10 & M & 49 & $\mathrm{II} / 4 / 7.0$ & LB, LE & $\mathrm{LE} / 24$ & $\begin{array}{l}\mathrm{LE}+\mathrm{UE}+\mathrm{F} / 18 \\
\text { symmetric }\end{array}$ & Yes/No & CV, GI, P, S & No/Yes/No & 19 & 176 \\
\hline 11 & $\mathrm{~F}$ & 42 & $\mathrm{I} / 36 / 10.4$ & LB & $\mathrm{LE} / 12$ & $\begin{array}{l}\mathrm{LE}+\mathrm{UE}+\mathrm{F} / 7 \\
\text { symmetric }\end{array}$ & Yes/Yes & CV, GI, P & No/Yes/Yes & 9 & 128 \\
\hline 12 & M & 66 & $\mathrm{II} / 5 / 8.3$ & LB & $\mathrm{LE} / 6$ & $\begin{array}{l}\mathrm{LE}>\mathrm{UE} / 4 \\
\text { symmetric }\end{array}$ & Yes/No & $\mathrm{CV}, \mathrm{GI}$ & $\mathrm{No} / \mathrm{No} / \mathrm{No}$ & 12 & 53 \\
\hline 13 & $\mathrm{~F}$ & 72 & $\mathrm{II} / 4 / 8.1$ & LB, UE & $\mathrm{LE}+\mathrm{UE} / 9$ & $\begin{array}{l}\mathrm{LE}+\mathrm{UE} / 4 \\
\text { asymmetric }\end{array}$ & Yes/No & & $\mathrm{No} / \mathrm{No} / \mathrm{No}$ & 13 & 73 \\
\hline 14 & M & 66 & $\mathrm{II} / 4 / 8.7$ & LB, LE & $\mathrm{LE} / 5$ & $\begin{array}{l}\mathrm{LE}>\mathrm{UE} / 5 \\
\text { asymmetric }\end{array}$ & Yes/No & CV, GI, S & $\mathrm{No} / \mathrm{Yes} / \mathrm{No}$ & 10 & 150 \\
\hline 15 & M & 68 & II/10/8.6 & LB, LE & $\mathrm{LE} / 4$ & $\begin{array}{l}\mathrm{LE}>\mathrm{UE} / 3 \\
\text { symmetric }\end{array}$ & $\mathrm{No} / \mathrm{No}$ & $\mathrm{CV}, \mathrm{S}$ & Yes/No/No & 9 & 140 \\
\hline
\end{tabular}


Table 2 Motor nerve conduction studies *

\begin{tabular}{|c|c|c|c|c|c|c|c|c|c|c|c|c|c|c|c|}
\hline Patient & 1 & 2 & 3 & 4 & 5 & 6 & 7 & 8 & 9 & 10 & 11 & 12 & 13 & 14 & 15 \\
\hline \multicolumn{16}{|l|}{ Median M: } \\
\hline $\mathrm{D} / \mathrm{P}(\mathrm{Amp} / \mathrm{mV})$ & $0.8 / 0.6$ & $3.2 / 2.4$ & & $6.2 / 5.6$ & $7.0 / 6.0$ & $6.1 / 5.7$ & $7.0 / 7.0$ & $2.0 / 1.5$ & $7.0 / 6.0$ & $4.2 / 3.4$ & & $5.1 / 5.0$ & $6.0 / 5.0$ & $2.7 / 1.4$ & $4.0 / 3.6$ \\
\hline $\mathrm{DL}(\mathrm{ms})$ & $\underline{8.0}$ & $\underline{7.1}$ & & $\underline{7.0}$ & $\underline{5.5}$ & $\underline{6.7}$ & 4.2 & 4.9 & 4.7 & 4.2 & & 3.8 & 4.5 & 3.4 & 4.6 \\
\hline $\mathrm{CV}(\mathrm{m} / \mathrm{s})$ & $\overline{24}$ & $\overline{31}$ & & $\overline{39}$ & $\overline{41}$ & $\overline{44}$ & 45 & 35 & 42 & 38 & & 47 & 50 & 49 & 50 \\
\hline $\mathrm{F}(\mathrm{ms})$ & $\overline{\mathrm{NR}}$ & $\overline{51}$ & & 44 & 39 & 41 & 29 & $\overline{N R}$ & 34 & 35 & & 35 & 32 & 30 & 32 \\
\hline \multicolumn{16}{|l|}{ Ulnar M: } \\
\hline $\begin{array}{l}\mathrm{D} / \mathrm{P}(\mathrm{Amp} / \\
\mathrm{mV})\end{array}$ & $0.7 / 0.5$ & $2.0 / 1.6$ & $4.0 / 3.0$ & $2.0 / 1.4$ & $4.0 / 3.0$ & & $10 / 9.7$ & $1.0 / 0.9$ & $6.0 / 5.0$ & $0.8 / 0.6$ & $1.0 / 0.9$ & $5.2 / 4.3$ & $3.5 / 3.1$ & $5.0 / 4.0$ & $4.5 / 4.0$ \\
\hline $\mathrm{DL}(\mathrm{ms})$ & 4.6 & 5.4 & 3.9 & 4.2 & 4.5 & & 3.0 & 3.8 & 4.3 & 4.3 & 6.3 & 3.8 & 4.3 & 3.3 & 3.8 \\
\hline $\mathrm{CV}(\mathrm{m} / \mathrm{s})$ & $\overline{36}$ & $\overline{36}$ & 48 & 41 & $\overline{35}$ & & 48 & 30 & 40 & 38 & $\overline{20}$ & 46 & 37 & 50 & 46 \\
\hline $\mathrm{F}(\mathrm{ms})$ & NR & $\underline{46}$ & 36 & $\underline{50}$ & $\overline{40}$ & & 31 & $\overline{\mathrm{NR}}$ & 37 & 36 & $\overline{\mathrm{NR}}$ & 39 & 38 & 31 & 33 \\
\hline \multicolumn{16}{|l|}{ Peroneal $\mathrm{M}+$ : } \\
\hline $\mathrm{D} / \mathrm{P}(\mathrm{Amp} / \mathrm{mV})$ & $1.0 / 0.8$ & NR & $0.4 / 0.3$ & $1.4 / 1.1$ & NR & $\underline{1.4 / 0.6}$ & $0.4 / 0.4$ & NR & $0.5 / 0.4$ & $0.3 / 0.2$ & $0.3 / 0.2$ & NR & $1.3 / 0.9$ & $1.9 / 1.4$ & $1.5 / 1.2$ \\
\hline $\mathrm{DL}(\mathrm{ms})$ & 5.5 & & 12.1 & 6.5 & & $\overline{7.1}$ & 6.7 & & 3.5 & 4.3 & 7.5 & & 6.2 & 4.4 & 5.3 \\
\hline $\mathrm{CV}(\mathrm{m} / \mathrm{s})$ & 38 & & 37 & $\overline{43}$ & & $\underline{32}$ & $\overline{42}$ & & 36 & 36 & 31 & & 36 & 35 & 41 \\
\hline $\mathrm{F}(\mathrm{ms})$ & NR & & NR & NR & & $\underline{70}$ & NR & & & NR & & & 50 & 62 & 56 \\
\hline \multicolumn{16}{|l|}{ Tibial M: } \\
\hline $\mathrm{D} / \mathrm{P}(\mathrm{Amp} / \mathrm{mV})$ & NR & & $0.6 / 0.4$ & NR & NR & $5.0 / 3.5$ & $\underline{1.9 / 0.8}$ & $0.8 / 0.6$ & NR & $0.6 / 0.5$ & NR & $2.0 / 1.5$ & $1.1 / 0.9$ & $4.1 / 3.3$ & $2.6 / 2.0$ \\
\hline $\mathrm{DL}(\mathrm{ms})$ & & & 5.1 & & & 6.5 & 6.2 & 6.3 & & 4.7 & & 5.9 & 5.3 & 5.3 & 5.0 \\
\hline $\mathrm{CV}(\mathrm{m} / \mathrm{s})$ & & & 35 & & & 31 & $\underline{30}$ & $\underline{31}$ & & 28 & & 34 & 44 & 39 & 44 \\
\hline $\mathrm{F}(\mathrm{ms})$ & & & NR & & & $\overline{72}$ & $\overline{62}$ & $\overline{\mathrm{NR}}$ & & $\overline{63}$ & & 70 & 32 & 59 & 52 \\
\hline
\end{tabular}

*Underlined values indicate electrophysiological demyelination.

$\dagger$ Recorded from the extensor digitorum brevis or anterior tibialis.

$\mathrm{D} / \mathrm{P}=\mathrm{Distal} /$ proximal; $\mathrm{NR}=$ no response

$\mathrm{ml} / \mathrm{kg}$ divided as above. Patients 10 to 15 received two courses of $2 \mathrm{~g} / \mathrm{kg}$ intravenous gammaglobulin (IVIg) 4 weeks apart. These treatment schedules are considered equivalent in efficacy when administered in immune therapies. ${ }^{13}$ Patients whose nerve biopsies showed dense periarterial inflammatory cells on routine non-immunological stains (patients 2,9 , and 15) received oral corticosteroids for 3 months (60 mg prednisone daily for 2 weeks and tapered by $10 \mathrm{mg}$ every 2 weeks). All these patients required the administration of insulin during corticosteroid therapy.

The clinical and laboratory data were evaluated statistically. The relation between clinical improvement and various factors was investigated with correlation analysis. The clinical statistical significance was determined as $\mathrm{p}<0.01$.

\section{Results}

The patients' clinical presentations, results of the neurological examination, and CSF analysis are summarised in table 1 . The sensory nerve conduction studies showed absent or markedly reduced amplitudes for all sural and ulnar nerves; the median and radial sensory nerves were similarly abnormal in all patients but two (7 and 8) who had low normal amplitudes. The results of the motor nerve conduction studies are listed in table 2. The autonomic function tests showed absent or reduced Q-SART responses distally, abnormal Valsalva ratio, and abnormal heart rate variation to deep breathing in all patients. Only six patients $(1,3,4,5,11$, and 15) had significant orthostatic hypotension (systolic blood pressure fall $\geqslant 30 \mathrm{~mm}$ ). The nerve biopsy findings are summarised in table 3 .

During the period of observation, all 15 patients improved, and we did not encounter clinical deterioration in any patient over 1 year (figure). Experience with large series of patients with diabetic neuropathy ${ }^{78}$ showed that an NDSW change of 5 points or more is clinically meaningful. We found that the mean change in absolute NDSW scores was significant and exceeded this value at all points of evaluation in this group of patients. The improvement in NDSW averaged 9.0 (SD 5.1) points at week 6, and 29.1 (SD 9.3) points by week 52 . When we considered the percentage of total change versus time, 55.5 (SD 12.1)\% of the improvement occurred in the first 12 weeks, and 80 (SD 7.2)\% occurred in the first 24 weeks of observation. There were no significant differences between the immunomodulating modalities (plasmapheresis $v$ IVIg).

We investigated the relation between clinical improvement (measured as percentage NDSW change from baseline) and various factors with correlation analysis. The clinical presentation

Table 3 Nerve biopsy findings

\begin{tabular}{|c|c|c|c|c|c|c|c|c|}
\hline No & $\begin{array}{l}\text { Density } \\
\text { of } M F\end{array}$ & $\begin{array}{l}\text { Endoneurial } \\
\text { oedema }\end{array}$ & $\begin{array}{l}\text { Onion } \\
\text { bulbs }\end{array}$ & Inflammatory cells & $\begin{array}{l}\text { Blood } \\
\text { vessels }\end{array}$ & $\begin{array}{l}\text { Segmental } \\
\text { demyelination }\end{array}$ & $\begin{array}{l}\text { Segmental } \\
\text { remyelination }\end{array}$ & $\begin{array}{l}\text { Axonal } \\
\text { degeneration }\end{array}$ \\
\hline 1 & 435 & Present & Absent & Absent & Thick BM & 11 & 9 & 12 \\
\hline 2 & 1850 & Present & Present & CD68, CD22, CD4, CD8 & Thick & 18 & 12 & 15 \\
\hline 3 & 830 & Present & Absent & Absent & Thick & 15 & 10 & 18 \\
\hline 4 & 780 & Present & Present & CD68 & Thick & 17 & 10 & 27 \\
\hline 5 & 285 & Absent & Absent & CD68 & Calcium & 24 & 17 & 18 \\
\hline 6 & 2530 & Absent & Absent & CD68 & Thick & 32 & 15 & 13 \\
\hline 7 & 960 & Present & Absent & $\mathrm{CD} 68, \mathrm{CD} 4, \mathrm{CD} 8$ & Thick & 18 & 6 & 16 \\
\hline 8 & 575 & Absent & Present & CD68 & Thick & 22 & 12 & 14 \\
\hline 9 & 715 & Present & Absent & $\mathrm{CD} 68, \mathrm{CD} 22, \mathrm{CD} 4, \mathrm{CD} 8$ & Thick & 14 & 15 & 16 \\
\hline 10 & 1220 & Present & Present & CD68 & Thick & 18 & 10 & 12 \\
\hline 12 & 605 & Present & Absent & Absent & Thick & 15 & 10 & 18 \\
\hline 13 & 1810 & Present & Absent & Absent & Thick & 12 & 15 & 18 \\
\hline 14 & 1314 & Absent & Absent & CD68 & Thick & 14 & 8 & 12 \\
\hline 15 & 1922 & Present & Absent & CD68, CD22, CD 4, CD8 & Occluded & 21 & 7 & 19 \\
\hline
\end{tabular}




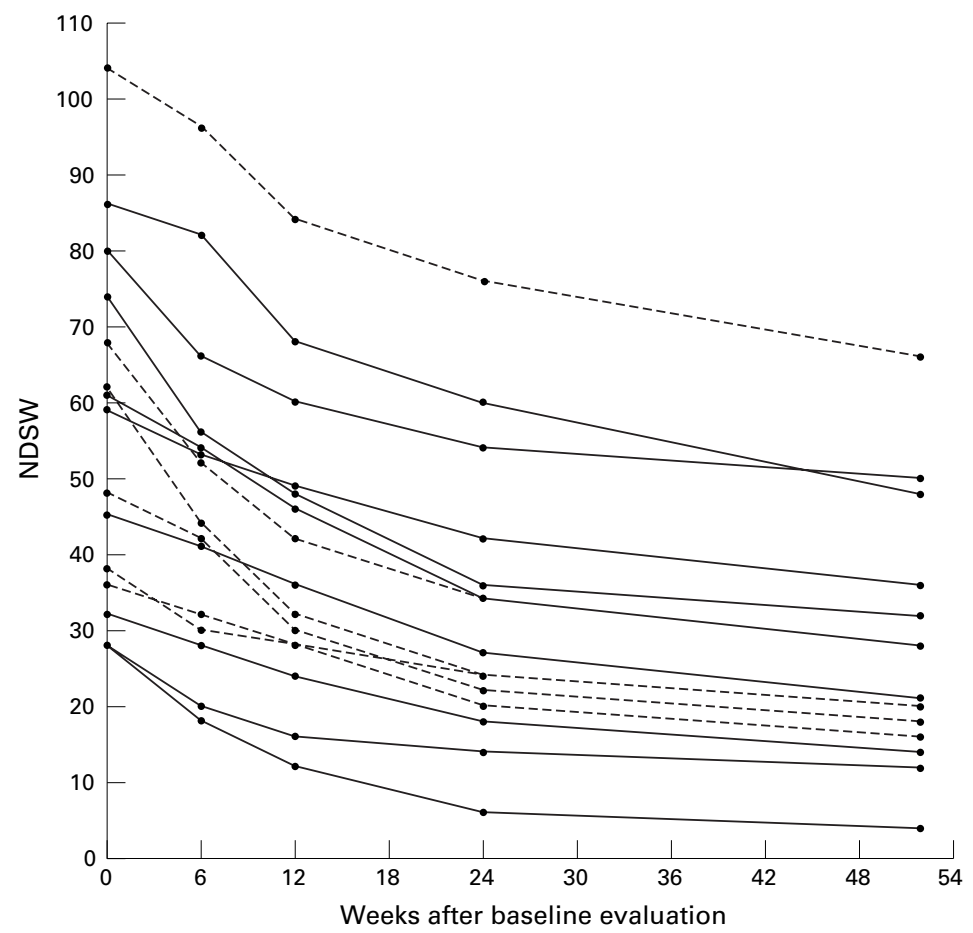

Neuropathy disability score: weakness subset (NDSW) for 15 diabetic patients with rapidly progressive polyradiculoneuropathy treated with immunomodulating therapy. Solid lines represent patients receiving plasmapheresis, dashed lines represent patients receiving intravenous gammaglobulin.

\section{Discussion}

The results of this study suggest that (1) certain diabetic patients with rapidly progressive polyradiculoneuropathy do respond rapidly to immunotherapy; (2) all patients improve without relapses for at least 1 year.

The therapeutic response in our diabetic patients was variable. There was definite improvement in the weakness subset of the neuropathy disability score in all patients. Only those with dense perivascular inflammatory infiltrates on routine stains were treated with prednisone and similar results were seen. All treated patients reported dramatic subjective improvement, in particular rapid resolution of their pain.

Our patients presented with accelerated proximal and distal weakness, hypoflexia or areflexia, and predominantly distal sensory loss. Several also had truncal and trigeminal sensory involvement consistent with a centripetal pattern of neuropathy. ${ }^{14}$ This deterioration occurred despite the lack of recent modification in their diabetic treatment and stable renal function. Twelve patients presented with clinically overt autonomic abnormalities that coincided with the exacerbation of their motor and sensory deficits. When evaluated by objective autonomic quantitative testing, all patients had significant abnormalities.

Several authors reported rapid deterioration in diabetic neuropathy. In a first series published in the form of an abstract, ${ }^{6}$ the authors suggested that these patients with rapidly progressive weakness may have concomitant chronic inflammatory demyelinating polyneuropathy and diabetes mellitus. Paradoxically, they found that patients overall did not respond to immunosuppressive therapy. Said et $a l^{3}$ described a rapidly progressive sensorimotor polyneuropathy in type I diabetes. The nerve biopsies showed excessive regeneration, and the authors suggested a metabolic abnormality. In their second study, Said et $a l^{4}$ described their findings in proximal asymmetric diabetic polyneuropathy. Inflammatory or vasculitic changes were present in several biopsies, and three patients responded to steroid treatment. Another series published in the form of an abstract ${ }^{15}$ reported 10 insulin dependent patients with rapid or slowly progressive weakness who variably responded to immunomodulating therapy; most were men and some had monoclonal proteins. Krendel et $a \bar{l}$ described 24 cases of diabetic neuropathy that responded to immunosuppressive treatment. They divided their patients into two groups: "an axonal form" in which the presentation was similar to that of patients with diabetic proximal neuropathy; and a "demyelinating form" in which the course and biopsy findings were similar to chronic inflammatory demyelinating polyneuropathy. Analysis of their electrophysiological data showed no difference between the groups. ${ }^{16}$ Several of their treated patients did not have CSF analysis or sural nerve evaluation, and no specified criteria were used to determine the implementation of immunosuppressive treatment. More recently, Stewart et $a l^{17}$ reported on seven 
diabetic patients with progressive and predominantly motor polyneuropathy who responded to immunomodulating therapy. Their patients met the electrophysiological criteria for chronic inflammatory demyelinating polyneuropathy and are therefore instances of chronic inflammatory demyelinating polyneuropathy in diabetes. In reviewing chronic inflammatory demyelinating polyneuropathy series, several authors found occasional cases associated with diabetes ${ }^{1819}$ and thought that they represented a mere coincidence.

Our patients presented in a manner similar to patients with chronic inflammatory demyelinating polyneuropathy. However, we think that there are several important differences.

Clinically, the proximal weakness was often asymmetric, and had a predilection for the L2-L4 myotomes in most patients. Nociceptive sensory loss often equalled or exceeded that of proprioceptive loss, and was present over the trunk in several patients. Radicular pain was pronounced and early. Weight loss was constant and rather marked. The autonomic abnormalities became prominent at the time of presentation. This association was found by others $^{34}$ and is rare in chronic inflammatory demyelinating polyneuropathy. ${ }^{20}$ Previous authors suggested an immunological basis for diabetic autonomic neuropathy. ${ }^{21-23}$ We found that the results of the autonomic tests predicted improvement at all points of study more reliably than nerve conduction studies. Several of these features suggest that patients with diabetes and rapidly progressive popyneuropathy may be more extended forms of BrunsGarland disease rather than chronic inflammatory demyelinating polyneuropathy. All our patients improved, and none worsened after the discontinuation of immunotherapy, a course that would not be expected in chronic inflammatory demyelinating polyneuropathy. ${ }^{2}$

Electrophysiologically, the nerve conduction and electromyographic studies were more often axonal, with signs of electrophysiological demyelination only in occasional nerve segments. Unlike other authors, ${ }^{17}$ we found electrophysiological conduction block without temporal dispersion in one patient only (case 14), an incidence similar to that found by another group when randomly screening diabetic patients. ${ }^{24}$ The proximal drop in the motor response amplitudes in patients 6 and 7 was associated with excessive temporal dispersion and could have been partly due to the axonal process. None of our patients fulfilled the ad hoc criteria ${ }^{10}$ for pure demyelinating polyneuropathy.

Pathologically, when compared with large series of patients with chronic inflammatory demyelinating polyneuropathy, ${ }^{18}$ the diabetic nerves of our patients had a similar incidence of axonal degeneration and demyelination, and whereas there were greater abnormalities involving the blood vessels, we concur with Stewart et $a l^{17}$ that these were not significantly distinctive. On immune staining, perivascular inflammatory infiltrates were present in 10 of 14 nerves. In agreement with another study, ${ }^{4}$ we did not find polymorphonuclear cells amidst the infiltrates. Unlike vasculitis, we did not find vascular wall necrosis. Our immunohistochemical staining disclosed a predominance of macrophage mediated demyelination indicating the activity of the neuropathy. The lymphocytic inflammatory infiltrates consisted predominantly of $\mathrm{T}$ cells, both helper and suppressor, a finding noted by others. ${ }^{25} \mathrm{We}$ encountered dense B lymphocytic infiltrates in three of 14 biopsies, an incidence similar to that found in two other series. ${ }^{17}{ }^{26}$ Although relatively uncommon, the B cells are present only in diabetic nerves and are not seen in chronic inflammatory demyelinating polyneuropathy. ${ }^{27}$ Finally, one nerve showed perineurial calcifications indicative of the chronicity of the neuropathy. ${ }^{29}$

On analysis of various confounding factors, the presence of significant autonomic dysfunction (heart rate change to breathing $<7 \mathrm{bpm}$; Q-SART over distal leg $<0.2 \mu \mathrm{l} / \mathrm{cm}^{2}$ ), and appreciable axonal loss (fibre density $<1000 /$ $\mathrm{mm}^{2}$ ) on sural nerve biopsies were independent poor prognostic factors. On the other hand, the presence of raised CSF protein $(>100 \mathrm{mg} / \mathrm{dl}$ ) and preserved ulnar motor conduction velocities $(>38 \mathrm{~m} / \mathrm{s})$ were good prognostic markers and predicted good and rapid therapeutic response. The presence of onion bulbs and of inflammatory infiltrates correlated with improvement of the absolute NDSW at weeks 6 and 12 respectively, but this effect was not found when NDSW\% change was considered.

Our preliminary results provide quantitative data about diabetes and PRN, and justify a prospective randomised study to determine whether immunotherapy can be beneficial in these instances. Although the tighter diabetic control during the study may have contributed to the clinical benefit, the improvement did not correlate with pretreatment diabetic control values. Also long term follow up is necessary to adequately evaluate the effect of immunosuppressive therapy. ${ }^{30}$ The issue of whether diabetes predisposes the peripheral nerve to immune attacks by exposing one or more antigens to the immune system is an intriguing on $\mathrm{e}^{31-33}$ but this could not be addressed by our study. Even in patients most responsive to immunomodulating therapy, we were unable to detect circulatory antibodies described in other immune neuropathies. ${ }^{34}$ This suggests that other endogenous and yet undetermined factors play an important part in the genesis of diabetes and rapidly progressive polyradiculoneuropathy. As the natural history of diabetic rapidly progressive polyradiculoneuropathy is uncertain, and because some patients will improve without immunomodulating therapy, our results are only suggestive of benefit with immunotherapy.

We thank Mrs Susan Danielson for performing the histological studies and Dr Anthony A Amato and Dr Richard J Barohn for reviewing the manuscript and providing helpful comments.

1 Thomas PK, Tomlinson DR. Diabetic and hypoglycemic neuropathy. In: Dyck PJ, Thomas PK, Griffin JW, et al, eds Peripheral neuropathy. Philadelphia: WB Saunders, Peripheral neurop

2 Dyck PJ, Kratz KM, Karnes JL, et al. The prevalence by staged severity of various types of diabetic neuropathy, 
retinopathy, and nephropathy in a population based cohort: the Rochester diabetic neuropathy study. Neurology 1993 the Rochester

3 Said G, Goulon-Goeau C, Lacroix C, et al. Severe early-onset polyneuropathy in insulin-dependant diabetes mellitus. N Engl F Med 1992;326:1257-63.

4 Said G, Goulon-Goeau C, Lacroix C, et al. Nerve biopsy findings in different patterns of proximal diabetic neuropathy. Ann Neurol 1994;35:559-69.

5 Krendel DA, Costigan DA, Hopkins LC. Successful treatment of neuropathies in patients with diabetes mellitus. Arch Neurol 1995;52:1053-61.

6 Cornblath DR, Drachman DB, Griffin JW. Demyelinating motor neuropathy in patients with diabetic polyneuropathy. Ann Neurol 1987;22:1.

7 Dyck PJ, Sherman WR, Hallcher LM, et al. Human diabetic endoneurial sorbitol, fructose, and myo-inositol related to sural nerve morphometry. Ann Neurol 1980;8:590-6.

8 Dyck PJ. Quantitating severity of neuropathy. In: Dyck PJ, Dyck PJ. Quantitating severity of neuropathy. In: Dyck PJ,
Thomas PK, Griffin JW, et al, eds. Peripheral neuropathy. Thomas PK, Griffin JW, et al, eds. Periph

9 Albers JW, Kelly JJ. Acquired inflammatory demyelinating polyneuropathies: clinical and electrodiagnostic features.

10 Cornblath DR, Asbury AK, Albers JW, et al. Research criteria for the diagnosis of chronic inflammmatory demyelinating polyneuropathy (CIDP). Report from an Ad Hoc Subcommittee of the American Academy of Neurology AIDS Task Force. Neurology 1991;41:617-18.

11 Low PA. Laboratory evaluation of autonomic failure. In Low PA, ed. Clinical autonomic disorders: evaluation and management. Boston: Little, Brown 1997:179-208.

12 Barohn RJ, Sahenk Z, Warmolts JR, et al. The BrunsGarland syndrome (diabetic amyotrophy) revisited 100 years later. Arch Neurol 1991;48:1130-5.

13 Dyck PJ, Litchy WJ, Kratz KM, et al. A plasma exchange versus immune globulin infusion trial in chronic inflammatory demyelinating polyradiculoneuropathy. Ann Neurol tory demyelinating

14 Said G, Slama G, Selva J. Progressive centripetal degeneration of axons in small fiber diabetic polyneuropathy. Brain tion of axons in sm

15 Engel WK, Prentice AF. Some polyneuropathies (Pns) in insulin-requiring adult-onset diabetes (IRAOD) can benefit remarkably from anti-dysimmune treatment. Neurology 1993;43:A255-6.

16 Walk D. Immunotherapy of neuropathies in patients with diabetes mellitus requires closer scrutiny. Arch Neurol 1996;53:590-1

17 Stewart JD, McKelvey R, Durcan L, et al. Chronic inflammatory demyelinating polyneuropathy (CIDP) in diabetics. F Neurol Sci 1996;142:59-64.

18 Barohn RJ, Kissel JT, Warmolts JR, et al. Chronic inflammmatory demyelinating polyradiculoneuropathy: clinical characteristics, course and recommendations for diagnostic criteria. Arch Neurol 1989;46:878-84.

19 Simmons Z, Albers JW, Bromberg MB, et al. Presentation and initial clinical course in patients with chronic inflammatory demyelinating polyneuropathy. Neurology 1993;43:2202-2209.

20 Ingall TJ, McLeod JG, Tamura N. Autonomic function and unmyelinated fibers in chronic inflammatory demyelinating polyradiculoneuropathy. Muscle Nerve 1990;13:70-6.

21 Guy RJC, Richards F, Edmonds ME, et al. Diabetic autonomic neuropathy and iritis: An association sugesting an immunological cause. BMF 1984;209:343-5.

22 Brown FM, Brink SJ, Freeman R, et al. Anti-sympathetic nervous system autoantibodies. Diminished catecholamines with orthostasis. Diabetes 1989;38:938-41.

23 Zanone MM, Peakman M, Purewal T, et al. Autoantibodies to nervous tissue structures are associated with autonomic neuropathy in type I (insulin-dependent) diabetes mellitus. Diabetologia 1993;36:564-9.

24 Abu-Shakra SR, Cornblath DR, Avila OL, et al. Conduction block in diabetic neuropathy. Muscle Nerve 1991;14:858

25 Younger DS, Rosoklija G, Hays AP, et al. Diabetic peripheral neuropathy: a clinicopathologic and immunohistochemical analysis of sural nerve biopsies. Muscle Nerve 1996;19:722-7.

26 Said G, Elgrably F, Lacroix C, et al. Painful proximal diabetic neuropathy: inflammtory nerve lesions and spontaneous favorable outcome. Ann Neurol 1997;41:762-70.

27 Pollard D, McCombe PA, Baverstock J, et al. Class II antigen expression and $\mathrm{T}$ lymphocyte subsets in chronic inflammatory demyelinating polyneuropathy. $\mathcal{F}$ Neuroimmunol 1986;13:123-34

28 Cornblath DR, Griffin DE, Welch D, et al. Quantitative analysis of endoneurial T-cells in human sural nerve biopsies. F Neuroimmunol 1990;26:113-18.

29 Van Lis JMJ, Jennekens GI, Veldman H. Calcium deposits in the perineurium and their relation to lipid accumulation $\mathscr{f}$ Neurol Sci 1979;43:367-75.

30 Kennedy WRR, Navarro X, Goetz FC, et al. Effects of pancreatic transplantation on diabetic neuropathy. $N$ Engl 7 Med 1990;322:1031-7.

31 Mancardi GL, Cadoni A, Zicca A, et al. HLA-DR Schwann cell reactivity in peripheral neuropathies of different origins. Neurology 1988;38:848-51.

32 Schróder HD, Olsson T, Solders G, et al. HLA-DR expressing cells and T-lymphocytes in sural nerve biopsies. Muscle Nerve 1988;11:864-70.

33 Vital C, Dumas P, Latinville D, et al. Relapsing inflammatory demyelinating polyneuropathy in a diabetic patient. Acta Neuropathol 1986;71:94-9.

34 Kornberg AJ, Pestronk A. The clinical and diagnostic role of anti-GM1 antibody testing. Muscle Nerve 1994;17:100-4. 